\title{
A Green Approach for the Synthesis of Silver Nanoparticles Using Ultrasonic Radiation's Times in Sodium Alginate Media: Characterization and Antibacterial Evaluation
}

\author{
Miftah Faried, ${ }^{1}$ Kamyar Shameli, ${ }^{1,2}$ Mikio Miyake, ${ }^{1}$ Abdollah Hajalilou, ${ }^{1}$ Ali Zamanian, \\ Zuriati Zakaria, ${ }^{1}$ Ebrahim Abouzari-lotf, ${ }^{1}$ Hirofumi Hara, ${ }^{1}$ \\ Nurul Bahiyah Bt Ahmad Khairudin, ${ }^{1}$ and Mariam Firdhaus Binti Mad Nordin ${ }^{1}$ \\ ${ }^{1}$ Department of Environment and Green Technology, Malaysia-Japan International Institute of Technology, \\ Universiti Teknologi Malaysia, Jalan Sultan Yahya Petra, 54100 Kuala Lumpur, Malaysia \\ ${ }^{2}$ Department of Nanotechnology and Advance Materials, Materials and Energy Research Center, P.O. Box 31787-316, \\ Karaj, Alborz, Iran
}

Correspondence should be addressed to Kamyar Shameli; kamyarshameli@gmail.com

Received 6 February 2016; Revised 13 May 2016; Accepted 9 June 2016

Academic Editor: Nathan C. Lindquist

Copyright (C) 2016 Miftah Faried et al. This is an open access article distributed under the Creative Commons Attribution License, which permits unrestricted use, distribution, and reproduction in any medium, provided the original work is properly cited.

The synthesis of silver nanoparticles (Ag-NPs) was achieved by a simple green chemistry procedure using sodium alginate (Na-Alg) under ultrasonic radiation as a stabilizer and physical reducing agent. The effect of radiation time on the synthesis of Ag-NPs was carried out at room temperature until $720 \mathrm{~min}$. The successful formation of Ag-NPs has been confirmed by UV-Vis, XRD, TEM, FESEM-EDX, zeta potential, and FT-IR analyses. The surface plasmon resonance band appeared at the range of $452-465 \mathrm{~nm}$ that is an evidence of formation of Ag-NPs. The XRD study showed that the particles are crystalline structure in nature, with a facecentered cubic ( $\mathrm{fcc}$ ) structure. The TEM study showed the Ag-NPs have average diameters of around 20.16-22.38 nm with spherical shape. The FESEM-EDX analysis confirmed the spherical shape of Ag-NPs on the surface of Alg and the element of Ag with the high purity. The zeta potential showed high stability of Alg/Ag-NPs especially after $720 \mathrm{~min}$ irradiation with value of $-67.56 \mathrm{mV}$. The FT-IR spectrum confirmed that the Ag-NPs have been capped by the Alg with van der Waals interaction. The Alg/Ag-NPs showed the antibacterial activity against Gram-positive and Gram-negative bacteria. These suggest that Ag-NPs can be employed as an effective bacteria inhibitor and can be applied in medical field.

\section{Introduction}

In recent years, nanotechnology and its uses are among the most excited research fields with application in many industrial parts. This is due to their unique physicochemical properties and another advantages such that they can be more specific and highly sensitive material for their selective applications [1]. Indeed, their applications have been applied in many technology areas, for instance, antimicrobial [2], immunology [3], and energy [4].

Synthesized metal nanoparticles are carried out by various chemical, physical, and biological methods, such as pyrolysis [5], chemical vapor deposition [6], and sol-gel [7]; that is, most of them use toxic reagent and are expensive. Therefore, high efforts in the synthesis of noble metal nanoparticles using environmentally friendly methods are required. These solutions generally are produced by the use of plant or fruit extracts and microorganism [8], which are cost-effective, time saving, and environmentally friendly [9].

Nanoparticles have distinguished physicochemical properties due to high surface reactivecenter, high mechanical strength, and electrical and thermal conductivity compared to the corresponding bulk material [10]. Ag-NPs have been exhibiting tremendous applications in the field of electronics [11], drug delivery [12], antimicrobial [13], and so on. However, the broad methods of the synthesis of Ag-NPs 
have been using chemical approach impacting environmental contamination risks [8]; providing a new physicochemical approach for saving synthesis of Ag-NPs is important.

Ultrasonic radiation is one of the famous irradiation methods for accelerating various organic reaction [14-16]. Also, sonochemical method, since discovered, has been studied for yielding kinds of nanomaterials, especially noble metal nanoparticles, such as $\mathrm{Ag}, \mathrm{Au}, \mathrm{Pt}$, and $\mathrm{Pb}$ producing nanoparticles [17]. Sonochemical technique can produce the acoustic cavitation during irradiation process then leading to the creation of free radical $[18,19]$. In the previous research, ultrasound irradiation has been involved in order to produce AgNPs using green algae of $P$. oedogonium (Mont.) Wittrock and seaweed $K$. alvarezii; however, using sodium alginate $(\mathrm{Na}-$ Alg) as the media was not reported $[20,21]$.

The Na-Alg is a natural carbohydrate polymer isolated from marine algae, considered to be biocompatible, nontoxic, and biodegradable. Mannuronic acid (M-block) and guluronic acid (G-block) units are the copolymer component in these algae arranged in an irregular block pattern: MM, GG, and MG blocks [22]. Many of free hydroxyl and carboxyl groups are distributed in their backbone of the Na-Alg [23].

Silver and silver based compounds are highly toxic to a number of microbial cells; otherwise, they have low toxicity for human cells [24]. Therefore, they can be an interesting part to be evaluated as the antibacterial activity. The AgNPs were reported recently as antibacterial agent against Escherichia coli and Staphylococcus aureus [25]. Thereby, $\mathrm{Alg} / \mathrm{Ag}-\mathrm{NPs}$ also have been evaluated for the application as the antimicrobial test. Based on previous researches, NaAlg has been prepared for the synthesized Ag-NPs by many different methods like green hydrothermal [22], microwaveassisted [26], and solution plasma process (SPP) [27].

However, there are no reports of ultrasonic radiation. Therefore, this study has proposed a green method of synthesizing Ag-NPs at room temperature by reducing $\mathrm{AgNO}_{3}$ on the Na-Alg for different ultrasonic radiation times. The Alg/Ag-NPs were optimized and characterized to study the effect of irradiation time on the surface plasmon resonance (SPR), structures, stability, and morphologies of the Alg/AgNPs. In addition, the application of these Alg/Ag-NPs has been also evaluated as antibacterial activity.

\section{Materials and Methods}

2.1. Materials. Silver nitrate $\left(\mathrm{AgNO}_{3}\right)$ with a percentage of 99.89\% (C0721-2284551) and sodium alginate (Na-Alg) were purchased from Bendosen and Acros (New Jersey, USA), respectively. Deionized water was used in all experiments from ELGA Lab-Water Purification System. Nutrient agar (NA) was used from Merck (Germany). All chemicals in this research were of analytical grade and without any purification.

2.2. Preparation of Silver Nanoparticles. An aqueous solution of $\mathrm{AgNO}_{3}(10 \mathrm{mM})$ was added to $400 \mathrm{~mL}$ of $\mathrm{Na}-\mathrm{Alg}(1.2 \mathrm{~g})$ in a beaker glass. Then, the Na-Alg solution was stirred until achieving the complete dissolving. Afterwards, the solution was exposed to a high-intensity ultrasound radiation ultrasonic processor (with probe-Ti horn) and placed around $2 \mathrm{~cm}$ from the bottom of the beaker which used the amplitude of $70 \%$ and the cycle of 0.5 from $15,30,60,90,120,180,240$, $420,480,540,600,660$, and $720 \mathrm{~min}$. Later, all solutions were kept in freezer to the next analysis and application without any washing. A control was prepared without irradiation to compare the effects of ultrasound. All of this reaction was conducted under ambient temperature.

2.3. Characterization of Silver Nanoparticles. The ultrasonic radiation was utilized by Hielscer UP-200S-RN, Germany (probe $1 \mathrm{~cm}$ of diameter), and the $\mathrm{pH}$ meter by $\mathrm{HACH}$ sensION (MM374) was used. The Alg/Ag-NPs were characterized by UV-Visible (UV-Vis) spectroscopy (UV-1800 Shimadzu) in the range of $300-800 \mathrm{~nm}$ to study the formation of nanoparticles. The crystalline structure of Alg/Ag-NPs was recorded by X-ray diffraction (XRD) at a scan of $2^{\circ} / \mathrm{min}$ of $5-80^{\circ}$ using Philips (X’pert, $\mathrm{Cu}-\mathrm{K} \alpha$ ). Transmission Electron Microscopy (TEM) analysis (Tecnai G2 F20 series) was carried out to examine the size and shape of the Alg/Ag-NPs. The morphology and the elemental atom of the nanoparticles were studied by Field Emission Scanning Electron Microcopy (FESEM) (JEOL-JSM-7600F) equipped with an Energy Dispersive X-ray (EDX) (XL 30 Philips Instruments). Zeta potential analyser (NanoPlus Zeta, Otsuka Electronics) determined the stability of the Alg/Ag-NPs. The Fourier transform-infrared (FT-IR) spectroscopy (NICOLET 6700) was recorded on spectrometer by ATR method and scanned range of $600-4000 \mathrm{~cm}^{-1}$.

2.4. Evaluation of Antibacterial Activity. The in vitro antibacterial evaluation of the Alg/Ag-NPs was studied using disc diffusion method, determining the inhibition zone in $\mathrm{mm}$. Then, it was confirmed according to the recommended standards of the National Committee for Clinical Laboratory Standards. Four pathogens that are two Gram-positive bacteria, Bacillus subtilis B29 and Staphylococcus aureus S276, and two Gram-negative bacteria, Escherichia coli E266 (the last three purchased from IMR) and Salmonella choleraesuis ATCC10708 (purchased from ATCC), were used for the antibacterial assay. The bacteria culture was standardized to $0.5 \mathrm{McFarland}$ standard which was approximately $10^{8}$ cells. Afterwards, the surface of the NA was completely inoculated using a sterile swab which was steeped in the prepared suspension of each bacterium. Then, sterile paper disc $(6 \mathrm{~mm})$ was immersed shortly to the Alg/Ag-NPs of 60, 120, 240, 480, and $720 \mathrm{~min}$ after irradiation, placed on the NA, and left to incubate at $30-37^{\circ} \mathrm{C}$ for $18-24$ hours. Streptomycin was used as the positive control in order to study the sensitivity of the bacteria and the sterile water as the negative control. After complete incubation, the diameter of the growth inhibition zones was measured including the disc. All these tests were done in triplicate.

\section{Results and Discussion}

A schematic illustration of this synthesized Alg/Ag-NPs method of ultrasonic radiation is presented in Figure 1. 


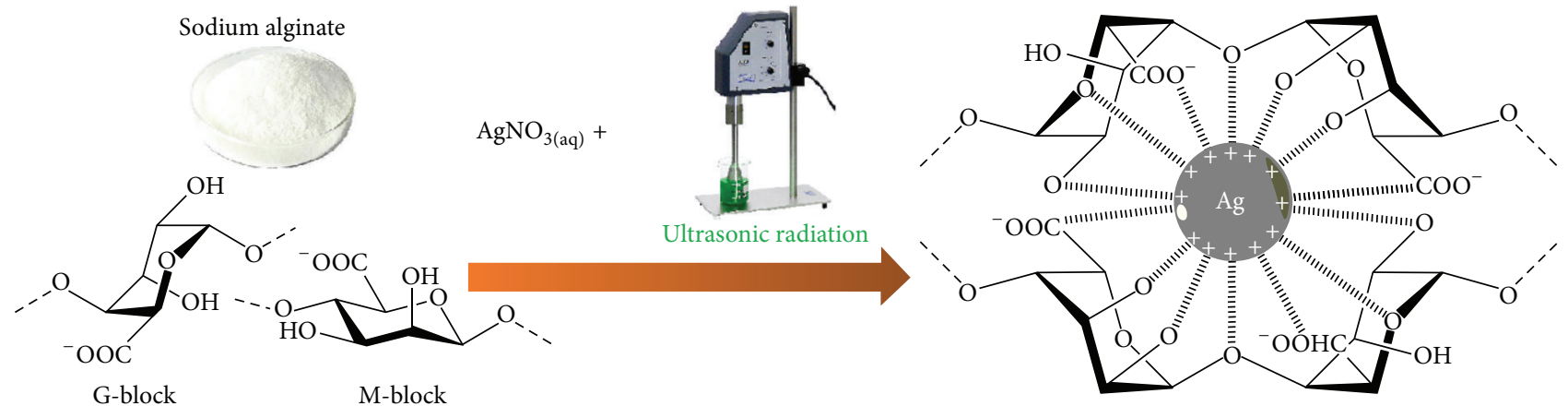

FIGURE 1: Schematic illustration of the synthesized Alg/Ag-NPs via ultrasonic radiation.

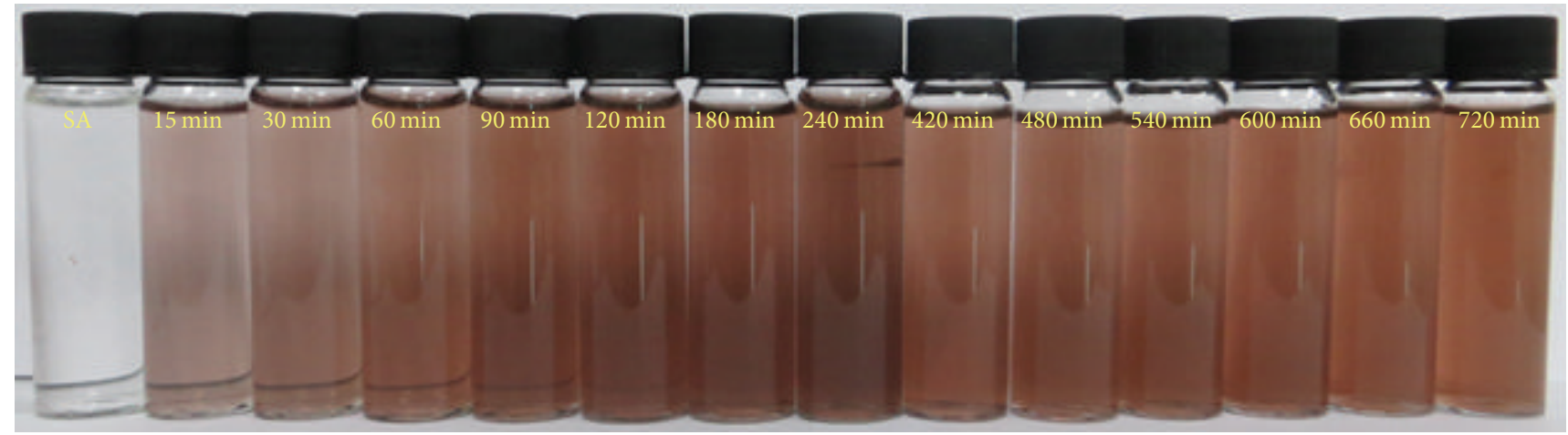

(a)

(b)

(c)

(d)

(e)

(f)

(g)

(h)

(i)

(j)

(k)

(1)

(m)

(n)

Figure 2: Photograph of Na-Alg (a) after ultrasonic irradiation for 15, 30, 60, 90, 120, 180, 240, 420, 480, 540, 600, 660, and 720 min ((b)-(n)), respectively.

The production of radicals of $\mathrm{H}^{\bullet}$ and $\mathrm{OH}^{\bullet}$ under ultrasonic radiation is notable and supported by $\mathrm{Alg}$ as the stabilizer caused this method to be a powerful technique as a green synthetic approach for synthesizing of Ag-NPs. The ultrasonic radiation is the main reducing agent in the producing $\mathrm{Ag}$ seed $\left(\mathrm{Ag}^{\circ}\right)$ capped by the Alg [17]. This equipment produces acoustic cavitation and bubble influencing the producing of local heating and high pressures $\left(\sim 5000^{\circ} \mathrm{C}\right.$ and $\sim 1000 \mathrm{~atm}$ ) and the following produced free-radicals [28]:

$$
\begin{aligned}
& n \mathrm{H}_{2} \mathrm{O} \stackrel{\text { Ultrasonic }}{\longrightarrow} n\left(\mathrm{H}^{\bullet}+{ }^{\bullet} \mathrm{OH}\right) \\
& \mathrm{AgNO}_{3} \stackrel{\text { Hydrolysis }}{\longrightarrow} \mathrm{Ag}^{+}+\mathrm{NO}_{3}^{-} \\
& \cdot \mathrm{OH}+\mathrm{RH} \longrightarrow \mathrm{R}^{\circ}+\mathrm{H}_{2} \mathrm{O} \\
& \mathrm{R}^{\bullet}+\mathrm{Ag}^{+} \longrightarrow \mathrm{Ag}^{\circ}+\mathrm{R}^{\prime}+\mathrm{H}^{+} \\
& \mathrm{H}^{\circ}+\mathrm{Ag}^{+} \stackrel{\text { Reduction }}{\longrightarrow} \mathrm{Ag}^{\circ}+\mathrm{H}^{+} \\
& \mathrm{Ag}^{+}+\mathrm{H}_{2} \mathrm{O} \longrightarrow \mathrm{Ag}^{\circ}+\mathrm{OH}^{\circ} \mathrm{H}^{+} \\
& n \mathrm{Ag}^{\circ} \longrightarrow\left(\mathrm{Ag}^{\circ}\right)_{n}(\text { aggregates }) \\
&(\mathrm{Ag})_{n}^{+} \longrightarrow\left(\mathrm{Ag}_{n-1}+\mathrm{Ag}^{+}\right.
\end{aligned}
$$

The mechanisms in producing Ag-NPs were firstly introduced by Nagata et al., shown in (1)-(6) [29]. In this reaction, hydroxyl groups from Alg contributed to bearing of $\mathrm{Ag}^{\circ}$ due to high-intensity ultrasonic radiation. Equations (7)-(8) are produced by high possibility of single silver atom to nuclei and grow to the Ag cluster as aggregation and/or disaggregation to the smaller nanoparticles [30]. Moreover, because of high concentration of produced $\mathrm{H}^{+}$ions, it related to decreasing of the $\mathrm{pH}$ which could show that before irradiation the $\mathrm{pH}$ was 8.72; however, after $720 \mathrm{~min}$ ultrasonic irradiation the $\mathrm{pH}$ became decreased to 6.05. The reduction of $\mathrm{Ag}^{+}$ ions was evidenced from the changing color before and after irradiation, shown in Figure 2. This positive indication of the formation of Ag-NPs will be discussed by the UV-Vis spectroscopy. The control study without irradiation did not show any different change of the color; therefore, this can indicate that ultrasound irradiation has been contributed in the producing Ag-NPs.

3.1. UV-Vis Spectroscopy Analysis. This equipment is the most widely used for structural characterization of the Ag-NPs. Figures 3 and 4 show the UV-Vis spectra after irradiation. For Figure 3, the absorption spectrum of the Alg/Ag-NPs prepared by ultrasonic irradiation shows a SPR band with a maximum of $452-465 \mathrm{~nm}$. This SPR indicated the presence of spherical or roughly spherical Ag-NPs [31]. By increasing 


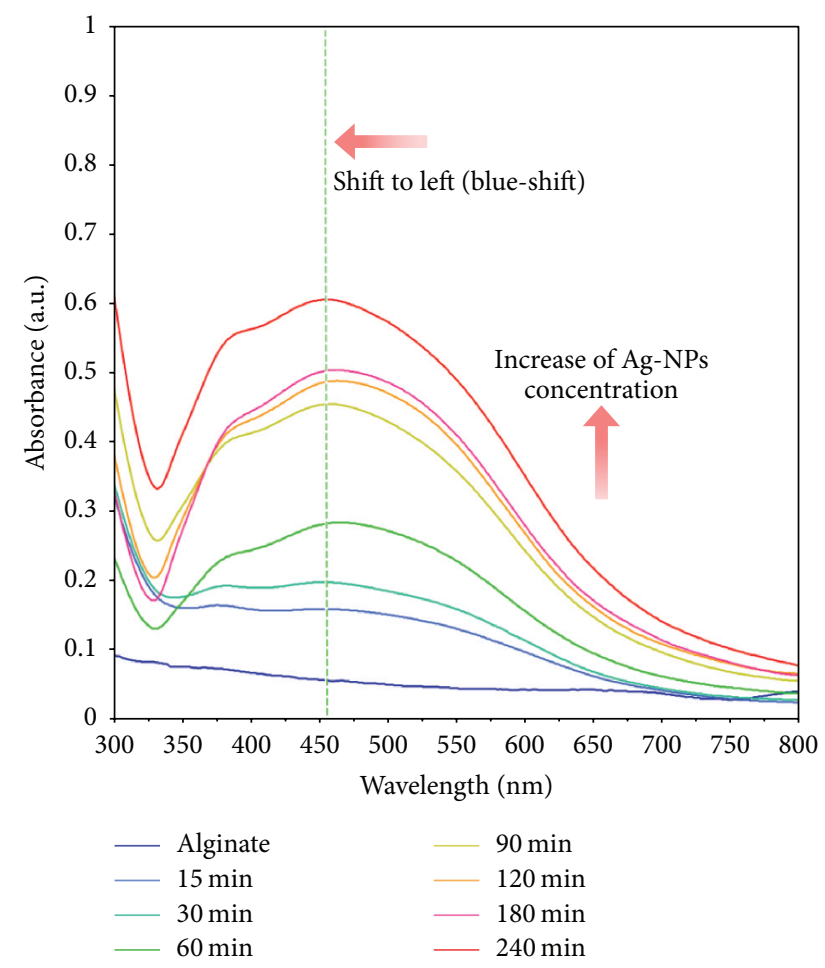

FIgURE 3: Time evolution UV-Vis spectra of Na-Alg and after irradiation from 15, 60, 90, 120, 180, and $240 \mathrm{~min}$.

irradiation time from 15 to $240 \mathrm{~min}$, the UV-Vis peaks intensity for Alg/Ag-NPs increased. Otherwise, the shifting occurred to the left side which is related to the blue-shift from $465,460,463,463,463,457$, and $452 \mathrm{~nm}$ for $15,30,60,90,120$, 180 , and $240 \mathrm{~min}$, according to Mei's theory that blue-shift influences the decreasing of the particle size [32]. In addition, an increasing concentration of the Alg/Ag-NPs happened due to the long time irradiation. These spectra were also supported by the previous research [33] that the SPR intensity could be increased by increasing time radiation.

Figure 4 shows the unique phenomenon that after 420 min of irradiation the Alg/Ag-NPs peak intensity compared with the previous period became decreased. This phenomenon was due to the agglomeration of Ag-NPs, because of their high specific surface area, thereby deteriorating their performances [34].

Despite that, the intensity of Alg/Ag-NPs became increased again in continuing irradiation until $720 \mathrm{~min}$ and associated with the increased concentration of Alg/Ag-NPs. However, no shifting occurred in the wavelength from 420 to $720 \mathrm{~min}$ which was represented as no change in the size of AgNPs [35]. The TEM images will be clarifying this observation after ultrasonic irradiation.

3.2. XRD Pattern Study. The crystallinity of Alg/Ag-NPs has been studied by the XRD pattern. Figure 5 shows the XRD pattern of Na-Alg and the Alg/Ag-NPs. Figure 5(a) indicates the peak at $13.91^{\circ}$ and $22.01^{\circ}$ which corresponded to the $\mathrm{Na}$ Alg structure. In addition, Figures 5(b) and 5(c) show the Alg/Ag-NPs after 240 and 720 min irradiation, respectively.

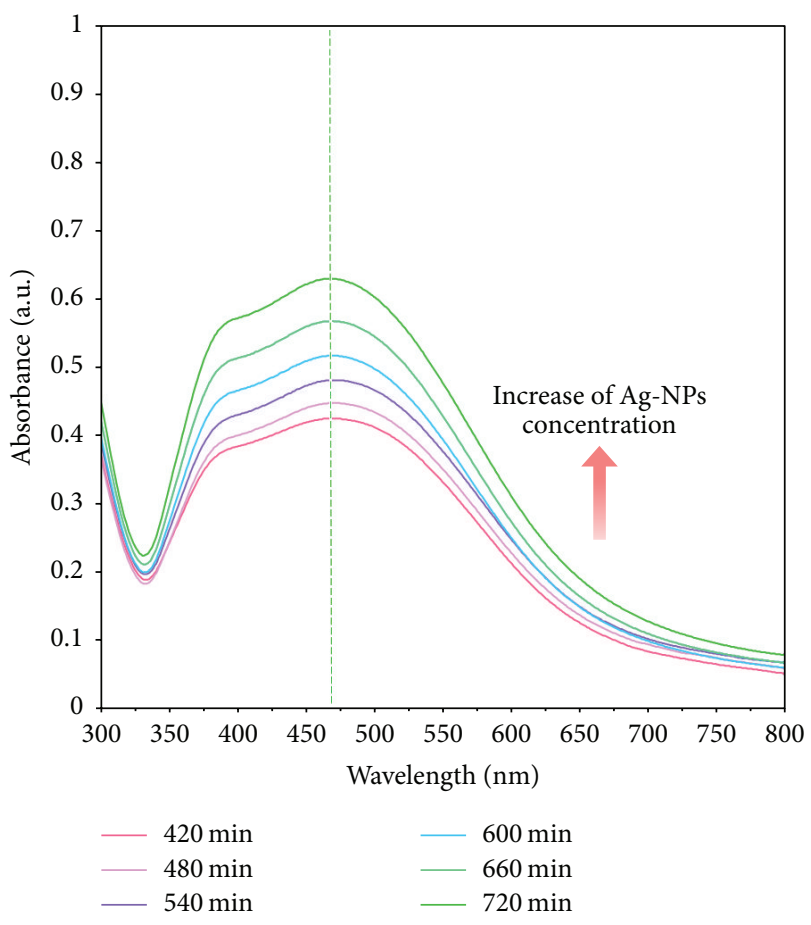

FIgUre 4: Time evolution UV-Vis spectra of the Alg/Ag-NPs from $420,480,540,600,660$, and 720 min irradiation.

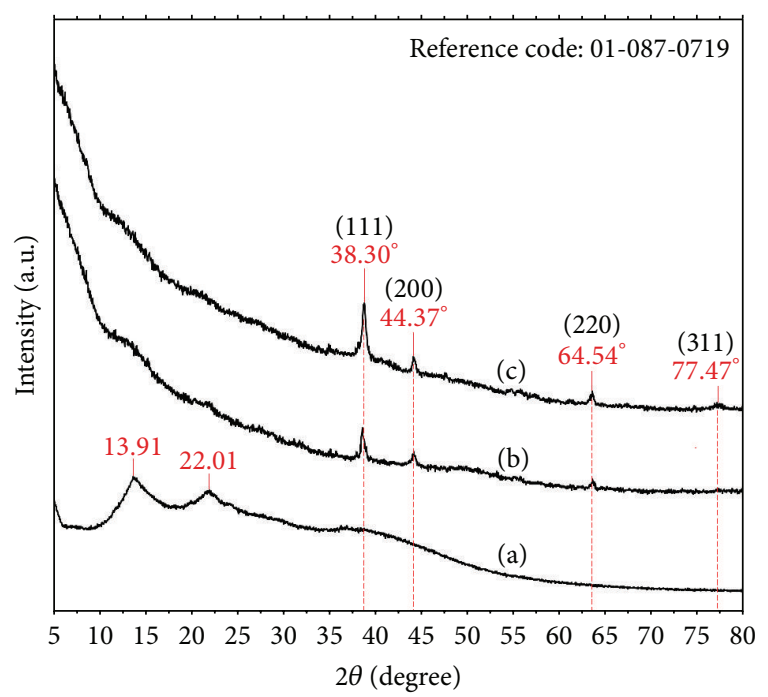

FIgURE 5: XRD pattern of the Na-Alg (a) and Alg/Ag-NPs after 240 and 720 min ultrasonic irradiation ((b)-(c)).

These two patterns show the peaks in $38.30^{\circ}, 44.37^{\circ}, 64.54^{\circ}$, and $77.47^{\circ}$ that could be attributed to (111), (200), (220), and (311) crystallographic planes of the face-centered cubic (fcc) structure. Based on reference database ICDD/ICSD from X’Pert High Score Plus (reference code: 01-087-0719), these peaks are specific compound to the crystalline of $\mathrm{Ag}$. Therefore, this material is the Alg/Ag-NPs without any impurities [36]. 

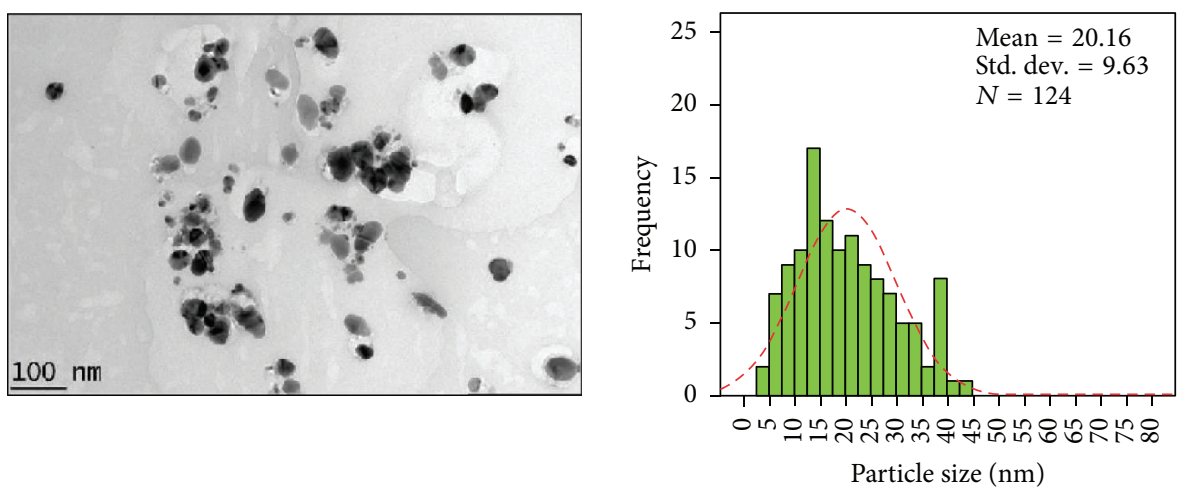

(a)
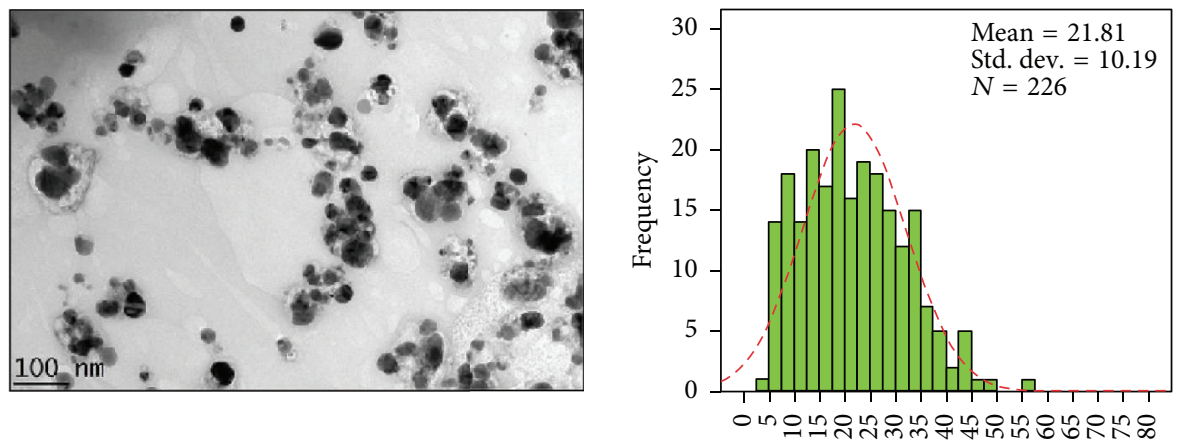

Particle size $(\mathrm{nm})$

(b)
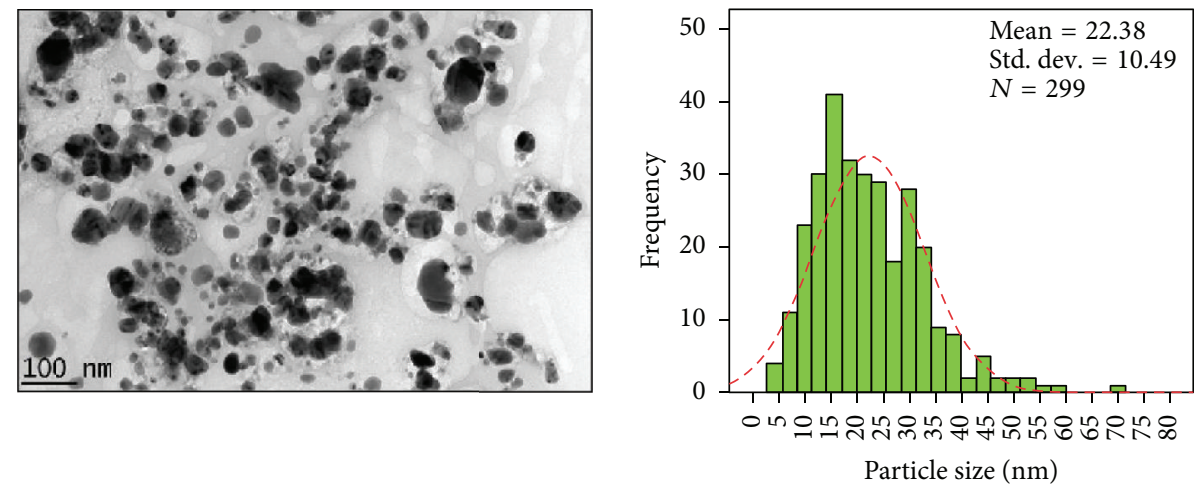

(c)

FIGURE 6: TEM images and their size distribution after 60, 240, and 720 min ultrasonic radiations ((a)-(c)).

The particle size has been calculated using DebyeScherrer equation:

$$
D=\frac{K \lambda}{\beta \cos \theta},
$$

where $D$ is the average crystalline particles size of Ag-NPs, $K$ is the Scherrer constant with value of $0.9, \lambda$ represents the X-ray wavelength (radiation/wavelength $\mathrm{Cu} K$-alpha is $0.154 \mathrm{~nm}$ ), and $\theta$ is the Bragg angle which is $2 \theta=38.30^{\circ}$, $\theta=19.15^{\circ}$. Herein, $\beta$ is the full width at half maximum of the diffraction peak. It can be found that the calculated average size is $14.04 \mathrm{~nm}$. This result has similarity to the XRD pattern of the Ag-NPs from waste using alkaline protease [37].
3.3. TEM Analysis. TEM images give valuable information about size and shape of the nanoparticles. Figure 6 represents the Alg/Ag-NPs after 60, 240, and 720 min ((a)-(c)) after ultrasonic radiations. These morphologies should be related to the different irradiation times. From all these results, the images show that the Ag-NPs are spherical in shape. However, they have different size of the Alg/Ag-NPs with the long time radiation, the size, and standard deviation being $20.16 \pm 9.63$, $21.81 \pm 10.19$, and $22.38 \pm 10.49 \mathrm{~nm}$ for 60,240 , and $720 \mathrm{~min}$ after irradiation, respectively.

Moreover, the number of the particles became increased with the following time radiation: 124, 226, and 299 for 60, 240 , and $720 \mathrm{~min}$, respectively. This increasing of number was 

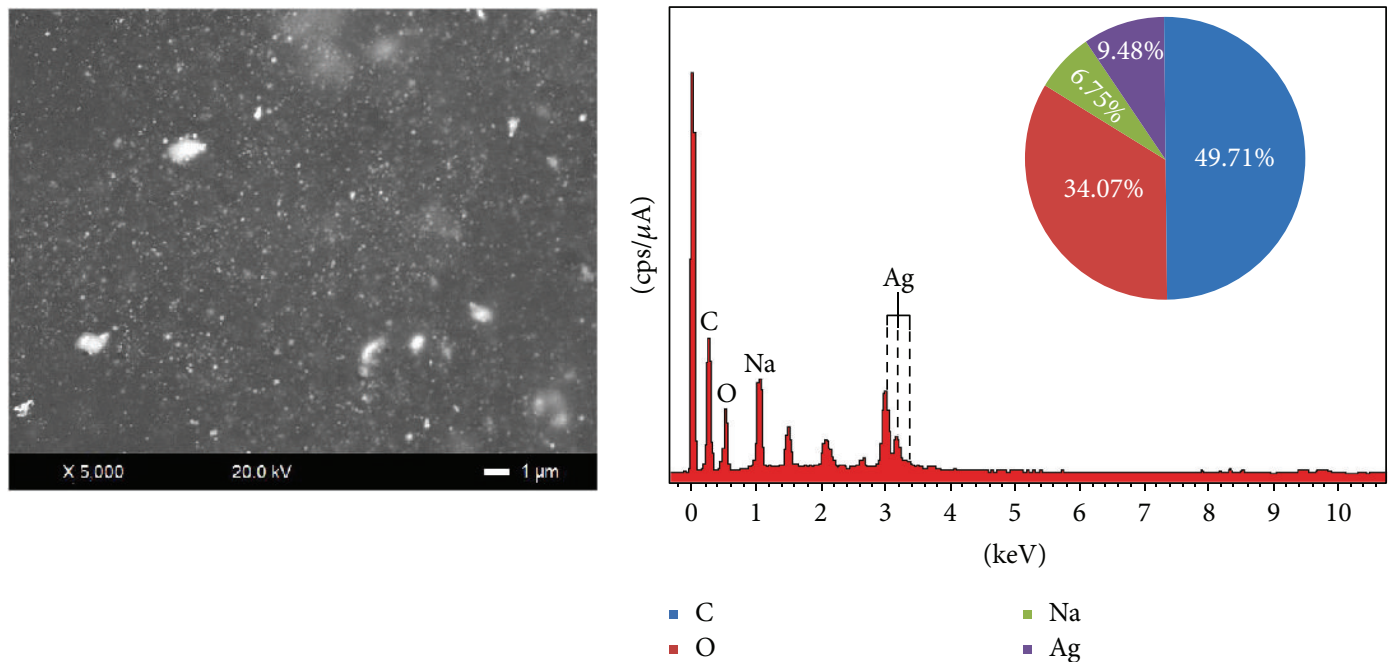

(a)
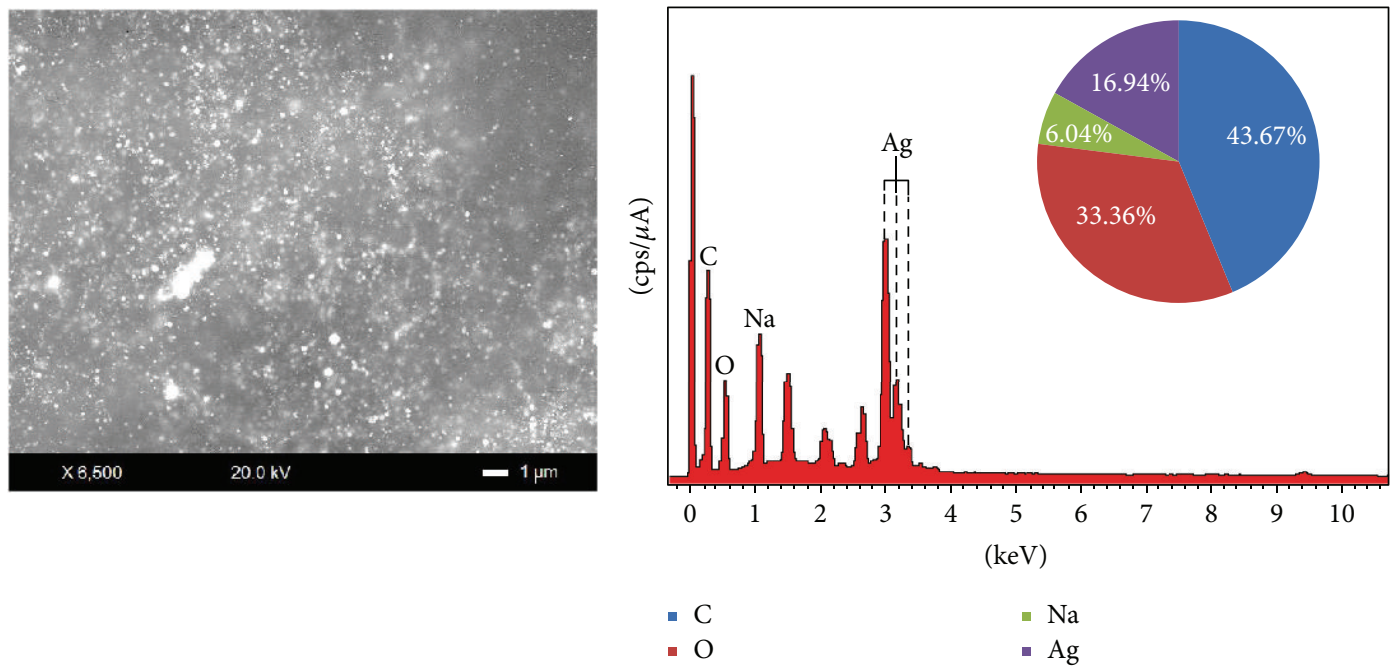

(b)

FIGURE 7: FESEM micrographs and EDX spectra of the Alg/Ag-NPs after 240 and 720 min irradiation ((a)-(b)).

due to the increasing of the concentration of Ag-NPs. In addition, SPR for UV-Vis spectra shows that the blue-shift appearance means that the size of particles decreases. However, TEM observation shows that the particle size almost increases by following irradiation times. This phenomenon was due to the agglomeration of the Ag-NPs which also occurred to Pant et al. on their synthesized Ag-NPs on polymer matrix $[29,33]$.

3.4. FESEM and EDX Analysis. The FESEM images have been used to study the surface morphology of media which can be shown in Figure 7. A narrow size distribution of Ag-NPs has been anchored and well distributed on the surface of Alg as the stabilizer. It illustrates that the particles are predominantly spherical and some of them aggregate into larger particles. This aggregation was due to the unique characteristic of AgNPs [34] which has been discussed before. This condition is considered by TEM observation that the nanoparticle became increased with the increasing irradiation times and some particles grew to be agglomerated. Moreover, Balavandy et al. [38] have investigated with the same condition as well that Ag-NPs fully covered the surface of media.

EDX spectroscopy was used to study the elemental atom of the nanoparticles which is shown in Figure 7. The spectra reveal strong signal in the silver region and confirm the formation of Alg/Ag-NPs which originated from the biomolecules of $\mathrm{Na}-\mathrm{Alg}$ as the media and also the presence of elemental Ag. Metallic silver generally shows typical optical absorption band at approximately 3.1, 3.3, and 3.4 KeV [39]. On the other hand, the signals of $\mathrm{O}, \mathrm{C}$, and $\mathrm{Na}$ in the EDX spectra were recorded from the Alg. The ratios of $\mathrm{C}, \mathrm{O}, \mathrm{Na}$, and $\mathrm{Ag}$ are $49.71 \%, 34.07 \%, 6.75 \%, 9.48 \%$ for $240 \mathrm{~min}$ and $43.67 \%, 33.36 \%, 6.04 \%$, and $16.94 \%$ for $720 \mathrm{~min}$, respectively. From the binding energy, no impurity is detected; therefore, this result reported that the product was composed of the high purity of Ag-NPs on the Alg as the stabilizer and it is 


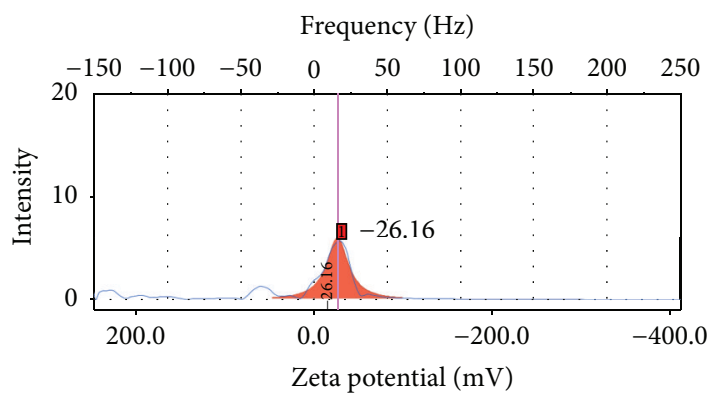

(a)

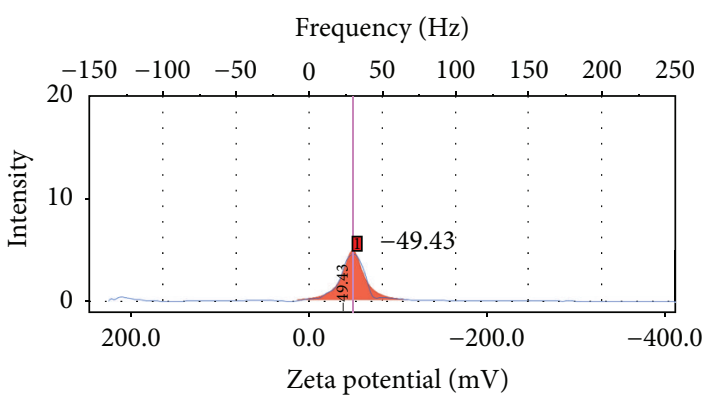

(b)

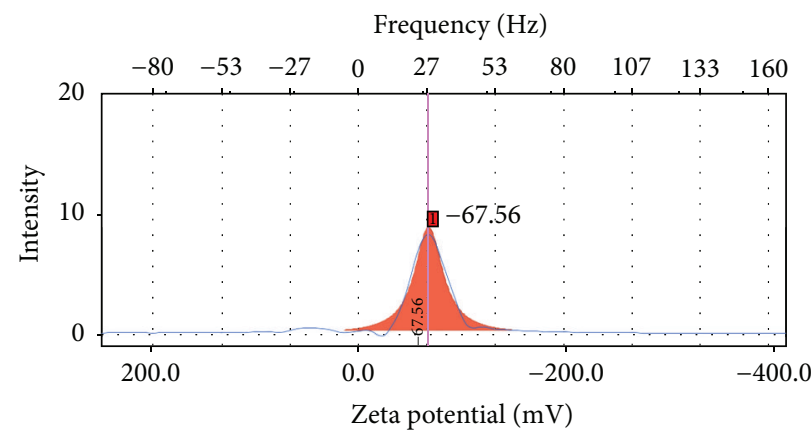

(c)

FIGURE 8: Zeta potential results for the sample of Na-Alg, 240 and $720 \mathrm{~min}((\mathrm{a})-(\mathrm{c}))$ after ultrasonic irradiation.

similar to the previous research that EDX data clearly shows the elemental silver on the media [40].

3.5. Zeta Potential Study. Zeta potential is equipment for studying the stability of the material under dispersion condition. It can be used as an important parameter for characterizing the electrical properties of the interfacial layer [41]. For the approximation, Smoluchowski method has been used as the method of this measurement. Figure 8 shows that zeta potential values were to be $-26.16,-49.43$, and $-67.56 \mathrm{mV}$ for $\mathrm{Na}-\mathrm{Alg}, 240$ and $720 \mathrm{~min}((\mathrm{a})-(\mathrm{c}))$ after ultrasonic radiation, respectively. This negative value is related to the presence of electronegative functional group from the Alg [42].

Based on ASTM for the stability colloidal suspension, the value between 30 and $40 \mathrm{mV}$ either positive or negative can indicate moderate stability; however, if the zeta value is more than $40 \mathrm{mV}$, it means a high stability suspension [43]. Thereby, this $\mathrm{Na}-\mathrm{Alg}$ was a moderate condition $(-26.16 \mathrm{mV})$ in Figure $8(\mathrm{a})$ due to unstable suspension under water solution. In addition, after treatment under ultrasonic radiation, the zeta potential value became increased to more than $-40 \mathrm{mV}$ which indicated the high stability of Alg/Ag-NPs especially after $720 \mathrm{~min}$ irradiation $(-67.56 \mathrm{mV})$. This zeta value was similar to that in the reported research by Sadeghi and Gholamhoseinpoor; however, they had studied Ag-NPs using Ziziphora tenuior $(Z t)$ extract [44].

3.6. FT-IR Analysis. The FT-IR measurements were carried out to identify the functional group of the material. Figure 9(a) shows the pure Na-Alg spectra with the characteristic band of $\mathrm{O}-\mathrm{H}$ stretching at $3252 \mathrm{~cm}^{-1}$ and $-\mathrm{COO}^{-}$(asymmetric) and $-\mathrm{COO}^{-}$(symmetric) at 1594,1407 , and $1297 \mathrm{~cm}^{-1}$ [45]. An intensive band at $1026 \mathrm{~cm}^{-1}$ is representing the stretching of C-O-C group; the peaks at $949 \mathrm{~cm}^{-1}, 885 \mathrm{~cm}^{-1}$, and $814 \mathrm{~cm}^{-1}$ belong to $\mathrm{C}-\mathrm{C}-\mathrm{H}$ stretching, $\mathrm{C}-\mathrm{O}-\mathrm{C}$ glycosidic linkage (ring breathing), and $-\mathrm{C}-\mathrm{C}$ (C-C-O ring) [46], respectively.

On the other hand, Figure $9((\mathrm{~b})-(\mathrm{c}))$ shows the spectra after ultrasonic irradiation for 240 and $720 \mathrm{~min}$. Views of new peaks at 1338 and $1341 \mathrm{~cm}^{-1}$ are $\mathrm{C}-\mathrm{H}$ and $\mathrm{C}-\mathrm{O}-\mathrm{H}$ due to ring stretching from the Alg with Ag-NPs. The comparison of FTIR spectra between the Alg and Alg/Ag-NPs showed only minor changes in the position as well as the absorption bands. Due to the Ag-NPs, the $\mathrm{O}-\mathrm{H}$ stretching vibration shifted from 3252 to $3257 \mathrm{~cm}^{-1}$ [47]. From some other shifting and decreasing peaks intensities in FT-IR peaks, there has been an absorption mechanism as interaction between Alg and AgNPs. Thereby, FT-IR spectrum confirms that Ag-NPs have been capped by the lone pair electrons around the oxygen atoms in organic compound in Alg with van der Waals interaction forces [48].

3.7. Evaluation of Antibacterial Activity. The antibacterial activity of Alg/Ag-NPs was evaluated against Staphylococcus aureus S276, Bacillus subtilis B29, Escherichia coli E266, and Salmonella choleraesuis ATCC10708 which are common in infectious diseases. The evaluation was done on the different irradiation times that are 60, 120, 240, 480, and $720 \mathrm{~min}$ after irradiation for (A1), (A2), (A3), (A4), and (A5), respectively, and the results are shown in Table 1 and Figure 10. From 


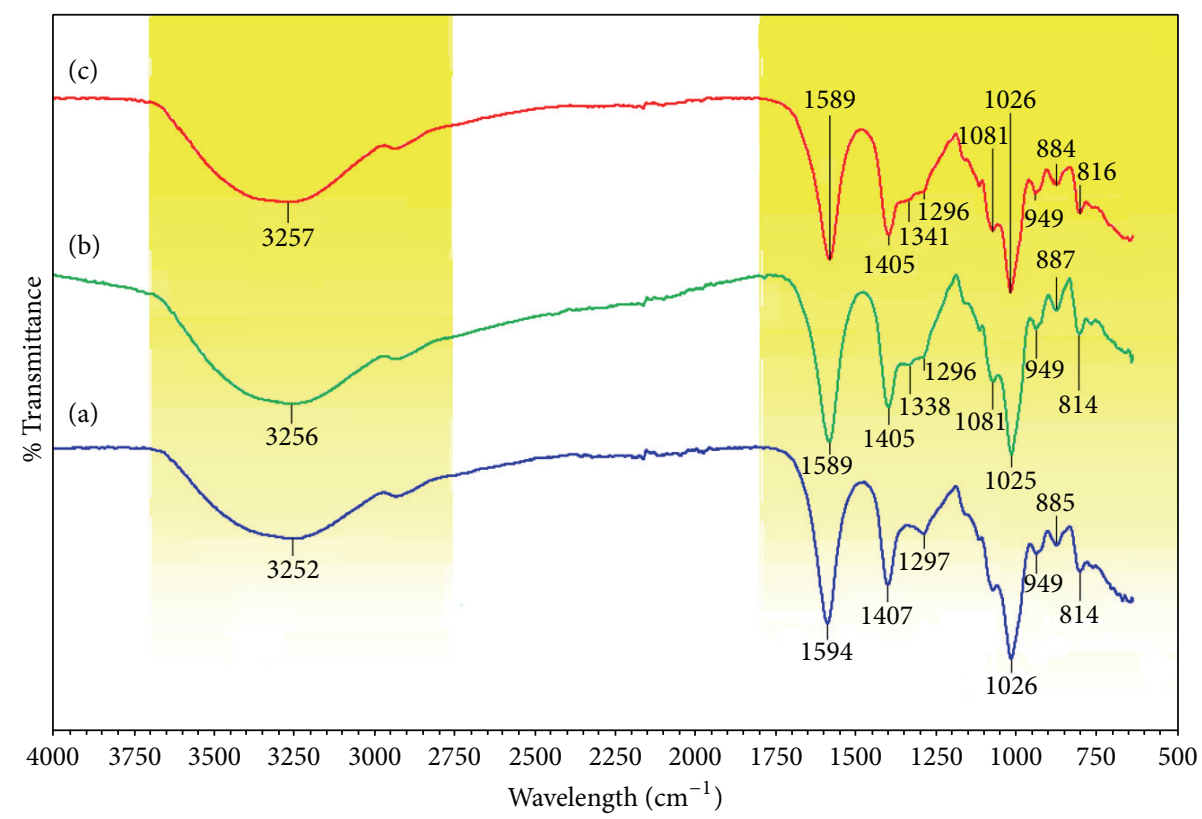

Figure 9: FT-IR spectrum of the Na-Alg, 240 and $720 \mathrm{~min}((\mathrm{a})-(\mathrm{c}))$ after irradiation.

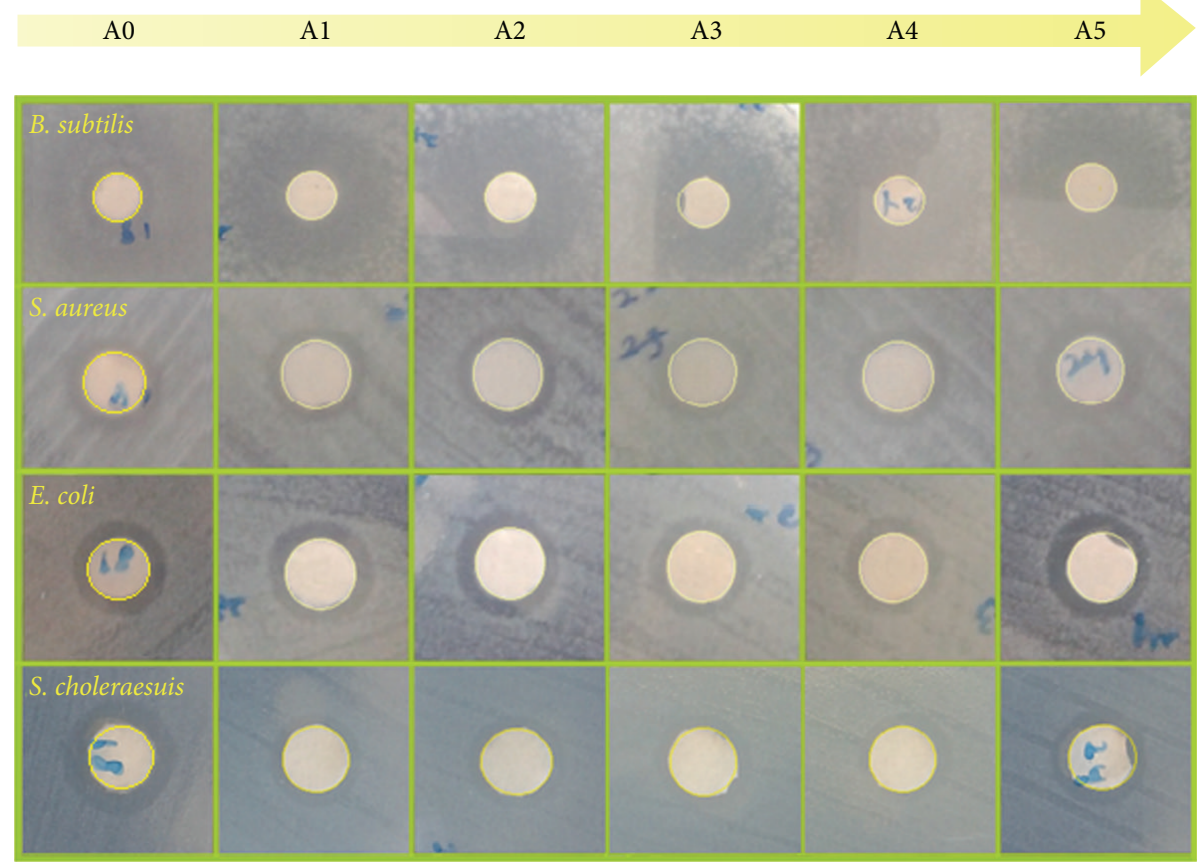

FIGURE 10: Comparison of the inhibition zone test for the antibacterial activity of Alg/Ag-NPs after different irradiation times: $\mathrm{AgNO}_{3} / \mathrm{Na}-$ Alg, 60, 120, 240, 480, and 720 min for A0, A1, A2, A3, A4, and A5 after ultrasonic irradiation.

Table 1, it can be understood that, by increasing irradiation times, the concentration of Alg/Ag-NPs became increased which is related to the UV-Vis and TEM results; then, it is responsible of increasing the antibacterial activity. The Alg/Ag-NPs have high antibacterial activity in all pathogens on both the Gram-positive and Gram-negative bacteria especially on B. subtilis B29 which is the strongest in this antibacterial test. This case on B. subtilis B29 is due to not having lipopolysaccharides in their body [49].

These high antibacterial activities are due to the nanosize of the Alg/Ag-NPs at $\sim 20 \mathrm{~nm}$ based on TEM observation. Thereby, it could be accumulated on the bacterial membrane, caused by their permeability, and resulted in cell death; and the positive charge of Ag ions was a crucial part as well to 
TABLE 1: Average inhibition zone for antibacterial activity of the Alg/Ag-NPs after different irradiation times.

\begin{tabular}{lcccccccc}
\hline \multirow{2}{*}{ Bacteria } & \multicolumn{4}{c}{ Inhibition zone $(\mathrm{mm})$} & \multicolumn{3}{c}{ Control negative (mm) } & Control positive (mm) \\
& A0 & A1 & A2 & A3 & A4 & A5 & Na-Alg & NA \\
B. subtilis (B29) & 9.8 & 18.1 & 18.3 & 18.8 & 19.1 & 20.9 & NA & 20.7 \\
S. aureus (S276) & 8.3 & 8.3 & 8.4 & 8.6 & 9.5 & 9.8 & NA & 23.6 \\
E. coli (E266) & 8.9 & 8.9 & 9.0 & 9.1 & 9.5 & 9.7 & NA & 21.8 \\
S. choleraesuis (ATCC10708) & 8.5 & 8.7 & 8.8 & 8.9 & 9.2 & 10.6 & 19.3 \\
\hline
\end{tabular}

Note. Mean standard deviation values for the $\mathrm{AgNO}_{3} / \mathrm{Na}-\mathrm{Alg} \pm 0.26 \mathrm{~mm}$, B. subtilis $\pm 0.57 \mathrm{~mm}$, S. aureus $\pm 0.24 \mathrm{~mm}$, E. coli $\pm 0.25 \mathrm{~mm}$, and S. choleraesuis \pm $0.22 \mathrm{~mm}$ for $\mathrm{AgNO}_{3} / \mathrm{Na}-\mathrm{Alg}, 60,120,240,480$, and $720 \mathrm{~min}$ for A0, A1, A2, A3, A4, and A5 after ultrasonic irradiation.

NA, not appearing; B. subtilis, Bacillus subtilis; S. aureus, Staphylococcus aureus; E. coli, Escherichia coli; S. choleraesuis, Salmonella choleraesuis; STM, streptomycin.

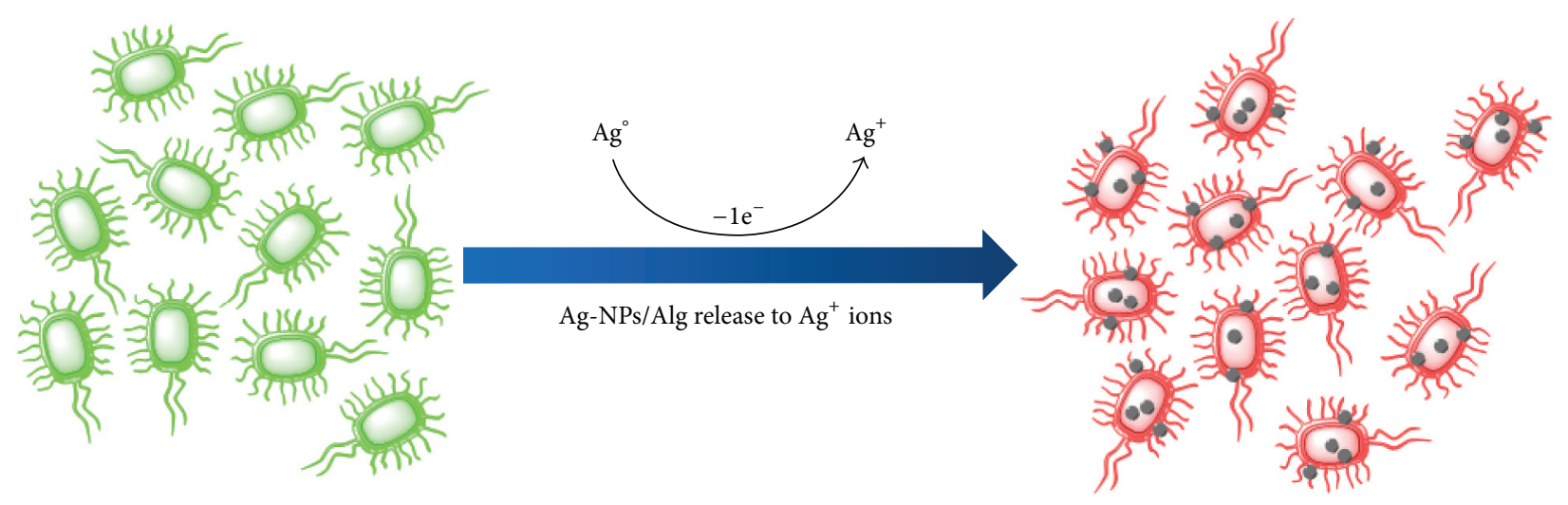

FIGURE 11: Schematic illustration of the mechanisms for their antibacterial activity (Alg/Ag-NPs).

this antibacterial activity [50]. This process can be illustrated in a schematic illustration shown in Figure 11. The similar potential to this as antibacterial agent from Ag-NPs has been studied using olive leaf extract [51].

\section{Conclusions}

In this study, Ag-NPs have been successfully prepared in Na-Alg following a green and physical reducing method under ultrasonic irradiation. The obtained SPR peaks for Ag-NPs appeared at around $467-473 \mathrm{~nm}$ by using UV-Vis spectroscopy. The XRD pattern also displayed the fcc crystal structure of the Ag-NPs without any impurities. TEM results indicated that the particle size of Ag-NPs almost increased with increasing ultrasonic irradiation times to be 20.16, 21.81, and $22.38 \mathrm{~nm}$ for 60,240 , and $720 \mathrm{~min}$. Zeta potential exhibited a high stability of Alg/Ag-NPs with value at $-67.56 \mathrm{mV}$ for $720 \mathrm{~min}$. Furthermore, the evaluation of the antibacterial activity shows the potential due to appearing inhibition zone for both Gram-positive bacteria and Gram-negative bacteria. Therefore, it could be concluded that the ultrasonic technique using Na-Alg has a remarkable potential for synthesizing Alg/Ag-NPs which is promising for antibacterial wound dressing such as surgical devices. In addition, long time irradiation is another part that should be improved in future works.

\section{Competing Interests}

All authors declare that they have agreed to publish this paper and that there are no competing interests.

\section{Acknowledgments}

This research was supported by the Malaysian Ministry of High Education and Universiti Teknologi Malaysia (UTM) under Fundamental Research Grant Scheme (FRGS) grant (Vot. no. 4F793). The authors also thank the Research Management Centre (RMC) of UTM for providing an excellent research environment to complete this work.

\section{References}

[1] G. Doria, J. Conde, B. Veigas et al., "Noble metal nanoparticles for biosensing applications," Sensors, vol. 12, no. 2, pp. 1657-1687, 2012.

[2] S. Prabhu and E. K. Poulose, "Silver nanoparticles: mechanism of antimicrobial action, synthesis, medical applications, and toxicity effects," International Nano Letters, vol. 2, no. 1, p. 32, 2012.

[3] D. M. Smith, J. K. Simon, and J. R. Baker Jr., "Applications of nanotechnology for immunology," Nature Reviews Immunology, vol. 13, no. 8, pp. 592-605, 2013.

[4] Z. Abdin, M. A. Alim, R. Saidur et al., "Solar energy harvesting with the application of nanotechnology," Renewable and Sustainable Energy Reviews, vol. 26, pp. 837-852, 2013. 
[5] K. R. Nemade and S. A. Waghuley, "Synthesis of MgO nanoparticles by solvent mixed spray pyrolysis technique for optical investigation," International Journal of Metals, vol. 2014, Article ID 389416, 4 pages, 2014.

[6] H. Alijani, M. H. Beyki, Z. Shariatinia, M. Bayat, and F. Shemirani, "A new approach for one step synthesis of magnetic carbon nanotubes/diatomite earth composite by chemical vapor deposition method: application for removal of lead ions," Chemical Engineering Journal, vol. 253, pp. 456-463, 2014.

[7] K. H. Leong, P. Monash, S. Ibrahim, and P. Saravanan, "Solar photocatalytic activity of anatase $\mathrm{TiO}_{2}$ nanocrystals synthesized by non-hydrolitic sol-gel method," Solar Energy, vol. 101, pp. 321-332, 2014.

[8] O. V. Kharissova, H. V. R. Dias, B. I. Kharisov, B. O. Pérez, and V. M. J. Pérez, "The greener synthesis of nanoparticles," Trends in Biotechnology, vol. 31, no. 4, pp. 240-248, 2013.

[9] V. V. Makarov, A. J. Love, O. V. Sinitsyna et al., "'Green' nanotechnologies: synthesis of metal nanoparticles using plants," Acta Naturae, vol. 6, no. 20, pp. 35-44, 2014.

[10] H. Mazaheri, M. Ghaedi, S. Hajati, K. Dashtian, and M. K. Purkait, "Simultaneous removal of methylene blue and $\mathrm{Pb}^{2+}$ ions using ruthenium nanoparticle-loaded activated carbon: response surface methodology," RSC Advances, vol. 5, no. 101, pp. 83427-83435, 2015.

[11] H. Yu, L. Li, and Y. Zhang, "Silver nanoparticle-based thermal interface materials with ultra-low thermal resistance for power electronics applications," Scripta Materialia, vol. 66, no. 11, pp. 931-934, 2012.

[12] L. A. Austin, M. A. MacKey, E. C. Dreaden, and M. A. El-Sayed, "The optical, photothermal, and facile surface chemical properties of gold and silver nanoparticles in biodiagnostics, therapy, and drug delivery," Archives of Toxicology, vol. 88, no. 7, pp. 13911417, 2014.

[13] M. B. Ahmad, K. Shameli, M. Y. Tay, M. Z. Hussein, and J. J. Lim, "Antibacterial effect of silver nanoparticles prepared in bipolymers at moderate temperature," Research on Chemical Intermediates, vol. 40, no. 2, pp. 817-832, 2014.

[14] M. Zakeri, M. M. Nasef, and E. Abouzari-Lotf, "Eco-safe and expeditious approaches for synthesis of quinazoline and pyrimidine-2-amine derivatives using ionic liquids aided with ultrasound or microwave irradiation," Journal of Molecular Liquids, vol. 199, pp. 267-274, 2014.

[15] M. Zakeri, M. M. Nasef, E. Abouzari-Lotf, and H. Haghi, "Ultrasound-assisted regioselective ring opening of epoxides with nitrogen heterocycles using pyrrolidonium and imidazolium-based acidic ionic liquids," Research on Chemical Intermediates, vol. 41, no. 12, pp. 10097-10108, 2015.

[16] M. M. Nasef, M. Zakeri, J. Asadi, E. Abouzari-Lotf, A. Ahmad, and R. Malakooti, "Environmentally benign and highly regioselective ring opening of epoxides accelerated by ultrasound irradiation," Green Chemistry Letters and Reviews, vol. 9, no. 1, pp. 76-84, 2016.

[17] C. He, L. Liu, Z. Fang, J. Li, J. Guo, and J. Wei, "Formation and characterization of silver nanoparticles in aqueous solution via ultrasonic irradiation," Ultrasonics Sonochemistry, vol. 21, no. 2, pp. 542-548, 2014.

[18] M. Faried, K. Shameli, M. Miyake et al., "Synthesis of silver nanoparticles via green method using ultrasound irradiation in seaweed Kappaphycus alvarezii media," Research on Chemical Intermediates, pp. 1-14, 2016.
[19] F. Nasiri Azad, M. Ghaedi, K. Dashtian, S. Hajati, A. Goudarzi, and M. Jamshidi, "Enhanced simultaneous removal of malachite green and safranin $\mathrm{O}$ by $\mathrm{ZnO}$ nanorod-loaded activated carbon: modeling, optimization and adsorption isotherms," New Journal of Chemistry, vol. 39, no. 10, pp. 7998-8005, 2015.

[20] S. N. Sinha, D. Paul, N. Halder, D. Sengupta, and S. K. Patra, "Green synthesis of silver nanoparticles using fresh water green alga Pithophora oedogonia (Mont.) Wittrock and evaluation of their antibacterial activity," Applied Nanoscience, vol. 5, no. 6, pp. 703-709, 2015.

[21] M. Faried, K. Shameli, M. Miyake, H. Hara, and N. B. A. Khairudin, "Green sonochemical synthesis of silver nanoparticles using marine seaweed as biopolymer media," Digest Journal of Nanomaterials and Biostructures, vol. 10, no. 4, pp. 1419-1426, 2015.

[22] J. Yang and J. Pan, "Hydrothermal synthesis of silver nanoparticles by sodium alginate and their applications in surfaceenhanced Raman scattering and catalysis," Acta Materialia, vol. 60, no. 12, pp. 4753-4758, 2012.

[23] J.-S. Yang, Y.-J. Xie, and W. He, "Research progress on chemical modification of alginate: a review," Carbohydrate Polymers, vol. 84, no. 1, pp. 33-39, 2011.

[24] A. Kumar, P. K. Vemula, P. M. Ajayan, and G. John, "Silvernanoparticle-embedded antimicrobial paints based on vegetable oil," Nature Materials, vol. 7, no. 3, pp. 236-241, 2008.

[25] K. Shameli, M. B. Ahmad, W. M. Z. W. Yunus et al., "Green synthesis of silver/montmorillonite/chitosan bionanocomposites using the UV irradiation method and evaluation of antibacterial activity," International Journal of Nanomedicine, vol. 5, no. 1, pp. 875-887, 2010.

[26] X. Zhao, Y. Xia, Q. Li et al., "Microwave-assisted synthesis of silver nanoparticles using sodium alginate and their antibacterial activity," Colloids and Surfaces A: Physicochemical and Engineering Aspects, vol. 444, pp. 180-188, 2014.

[27] S. Nam, D. MubarakAli, and J. Kim, "Characterization of alginate/silver nanobiocomposites synthesized by solution plasma process and their antimicrobial properties," Journal of Nanomaterials, vol. 2016, Article ID 4712813, 9 pages, 2016.

[28] A. M. Golsheikh, N. M. Huang, H. N. Lim, and R. Zakaria, "One-pot sonochemical synthesis of reduced graphene oxide uniformly decorated with ultrafine silver nanoparticles for nonenzymatic detection of $\mathrm{H}_{2} \mathrm{O}_{2}$ and optical detection of mercury ions," RSC Advances, vol. 4, no. 69, pp. 36401-36411, 2014.

[29] Y. Nagata, Y. Watananabe, S.-I. Fujita, T. Dohmaru, and S. Taniguchi, "Formation of colloidal silver in water by ultrasonic irradiation," Journal of the Chemical Society, Chemical Communications, no. 21, pp. 1620-1622, 1992.

[30] M. Darroudi, M. B. Ahmad, K. Shameli, A. H. Abdullah, and N. A. Ibrahim, "Synthesis and characterization of UV-irradiated silver/montmorillonite nanocomposites," Solid State Sciences, vol. 11, no. 9, pp. 1621-1624, 2009.

[31] D. He, A. M. Jones, S. Garg, A. N. Pharm, and T. D. Waite, "Silver nanoparticle-reactive oxygen species interactions: application of a charging-discharging model," The Journal of Physical Chemistry C, vol. 115, pp. 5461-5468, 2011.

[32] R. Wang, J. Lang, Y. Liu, Z. Lin, and X. Yan, "Ultra-small, sizecontrolled $\mathrm{Ni}(\mathrm{OH})_{2}$ nanoparticles: elucidating the relationship between particle size and electrochemical performance for advanced energy storage devices," NPG Asia Materials, vol. 7, article e183, 2015.

[33] M. Darroudi, A. Khorsand Zak, M. R. Muhamad, N. M. Huang, and M. Hakimi, "Green synthesis of colloidal silver 
nanoparticles by sonochemical method," Materials Letters, vol. 66, no. 1, pp. 117-120, 2012.

[34] L. Wang, J. Li, D. Wang, D. Wang, and H. Li, "Preparation and properties of core-shell silver/polyimide nanocomposites," Polymer Bulletin, vol. 71, no. 10, pp. 2661-2670, 2014.

[35] C. Raimondo, B. Kenens, F. Reinders, M. Mayor, H. Uji-I, and P. Samorì, "Au nanoparticle scaffolds modulating intermolecular interactions among the conjugated azobenzenes chemisorbed on curved surfaces: tuning the kinetics of cis-trans isomerisation," Nanoscale, vol. 7, no. 33, pp. 13836-13839, 2015.

[36] S. Chidambaram, B. Pari, N. Kasi, and S. Muthusamy, “ $\mathrm{ZnO} / \mathrm{Ag}$ heterostructures embedded in $\mathrm{Fe}_{3} \mathrm{O}_{4}$ nanoparticles for magnetically recoverable photocatalysis," Journal of Alloys and Compounds, vol. 665, pp. 404-410, 2016.

[37] S. Shankar, R. G. S. V. Prasad, P. R. Selvakannan, L. Jaiswal, and R. S. Laxman, "Green synthesis of silver nanoribbons from waste X-ray films using alkaline protease," Materials Express, vol. 5, no. 2, pp. 165-170, 2015.

[38] S. K. Balavandy, K. Shameli, and Z. Z. Abidin, "Rapid and green synthesis of silver nanoparticles via sodium alginate media," International Journal of Electrochemical Science, vol. 10, no. 1, pp. 486-497, 2015.

[39] K. Shameli, M. Bin Ahmad, E. A. J. Al-Mulla, P. Shabanzadeh, and S. Bagheri, "Antibacterial effect of silver nanoparticles on talc composites," Research on Chemical Intermediates, vol. 41, no. 1, pp. 251-263, 2015.

[40] G. Ciobanu, S. Ilisei, and C. Luca, "Hydroxyapatite-silver nanoparticles coatings on porous polyurethane scaffold," Materials Science and Engineering C, vol. 35, no. 1, pp. 36-42, 2014.

[41] A. Sze, D. Erickson, L. Ren, and D. Li, "Zeta-potential measurement using the Smoluchowski equation and the slope of the current-time relationship in electroosmotic flow," Journal of Colloid and Interface Science, vol. 261, no. 2, pp. 402-410, 2003.

[42] V. Chakrapani, J. C. Angus, A. B. Anderson, S. D. Wolter, B. R. Stoner, and G. U. Sumanasekera, "Charge transfer equilibria between diamond and an aqueous oxygen electrochemical redox couple," Science, vol. 318, no. 5855, pp. 1424-1430, 2007.

[43] J. I. Kwak, W.-M. Lee, S. W. Kim, and Y.-J. An, "Interaction of citrate-coated silver nanoparticles with earthworm coelomic fluid and related cytotoxicity in Eisenia andrei," Journal of Applied Toxicology, vol. 34, no. 11, pp. 1145-1154, 2014.

[44] B. Sadeghi and F. Gholamhoseinpoor, "A study on the stability and green synthesis of silver nanoparticles using Ziziphora tenuior (Zt) extract at room temperature," Spectrochimica Acta-Part A: Molecular and Biomolecular Spectroscopy, vol. 134, pp. 310-315, 2015.

[45] A. Manuja, S. Kumar, N. Dilbaghi et al., "Quinapyramine sulfate-loaded sodium alginate nanoparticles show enhanced trypanocidal activity," Nanomedicine, vol. 9, no. 11, pp. 16251634, 2014.

[46] G. Cardenas-Jiron, D. Leal, B. Matsuhiro, and I. O. OsorioRoman, "Vibrational spectroscopy and density functional theory calculations of poly-D-mannuronate and heteropolymeric fractions from sodium alginate," Journal of Raman Spectroscopy, vol. 42, no. 4, pp. 870-878, 2011.

[47] V. Gopinath, D. MubarakAli, S. Priyadarshini, N. M. Priyadharsshini, N. Thajuddin, and P. Velusamy, "Biosynthesis of silver nanoparticles from Tribulus terrestris and its antimicrobial activity: a novel biological approach," Colloids and Surfaces B: Biointerfaces, vol. 96, pp. 69-74, 2012.

[48] A. Mandal, S. Sekar, N. Chandrasekaran, A. Mukherjee, and T. P. Sastry, "Vibrational spectroscopic investigation on interaction of sago starch capped silver nanoparticles with collagen: a comparative physicochemical study using FT-IR and FT-Raman techniques," RSC Advances, vol. 5, no. 21, pp. 15763-15771, 2015.

[49] J. Wu, Y. Zheng, W. Song et al., "In situ synthesis of silvernanoparticles/bacterial cellulose composites for slow-released antimicrobial wound dressing," Carbohydrate Polymers, vol. 102, no. 1, pp. 762-771, 2014.

[50] K. Shameli, M. Bin Ahmad, M. Zargar et al., "Synthesis and characterization of silver/montmorillonite/chitosan bionanocomposites by chemical reduction method and their antibacterial activity," Journal of International Journal of Nanomedicine, vol. 6, no. 2, pp. 271-284, 2011.

[51] M. M. H. Khalil, E. H. Ismail, K. Z. El-Baghdady, and D. Mohamed, "Green synthesis of silver nanoparticles using olive leaf extract and its antibacterial activity," Arabian Journal of Chemistry, vol. 7, no. 6, pp. 1131-1139, 2014. 

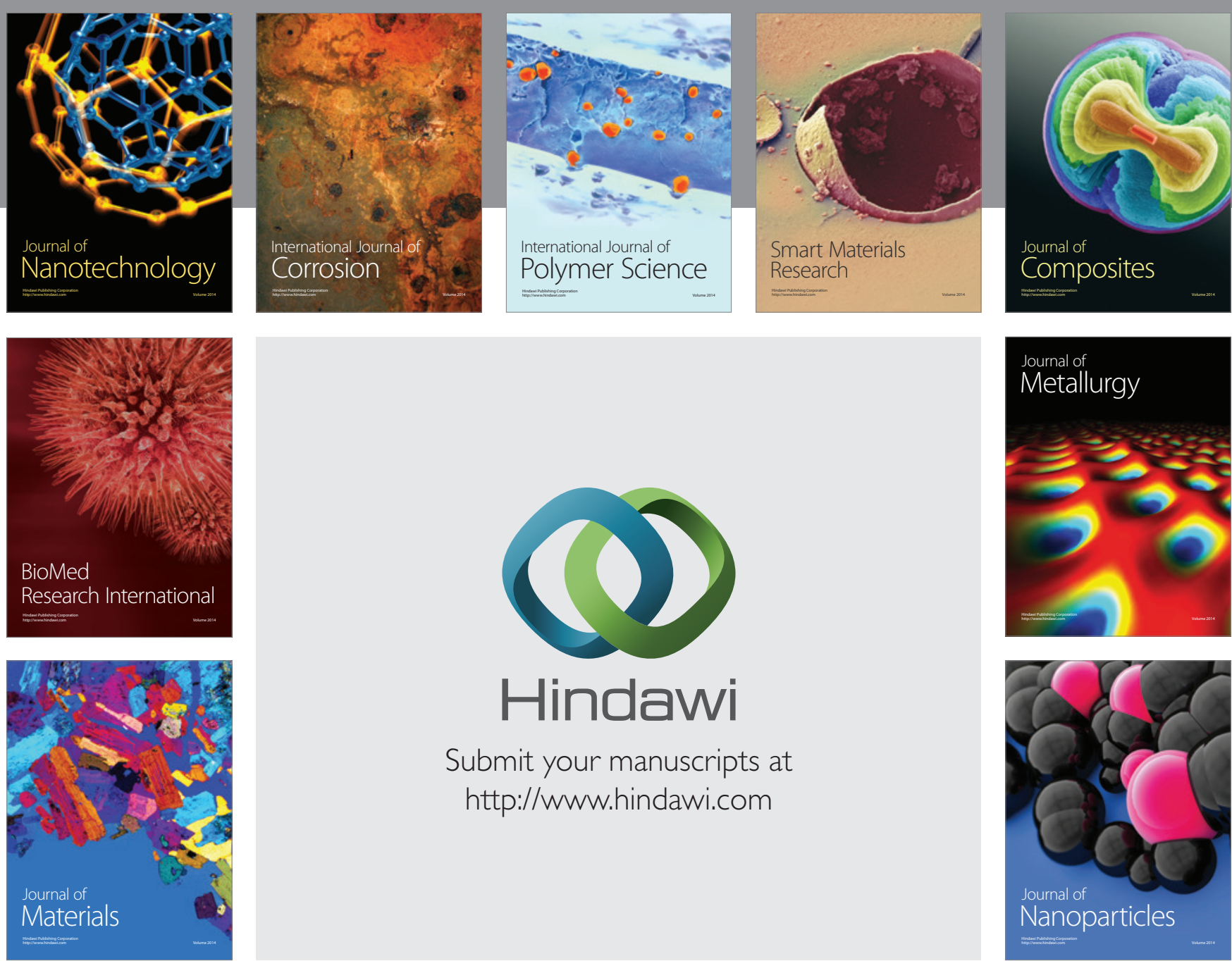

\section{Hindawi}

Submit your manuscripts at

http://www.hindawi.com

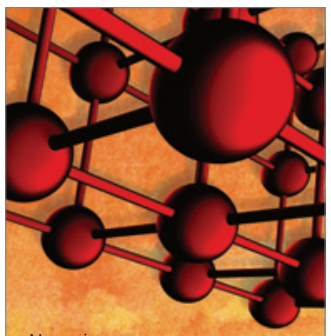

Materials Science and Engineering
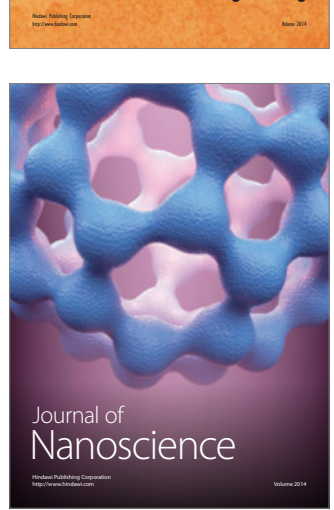
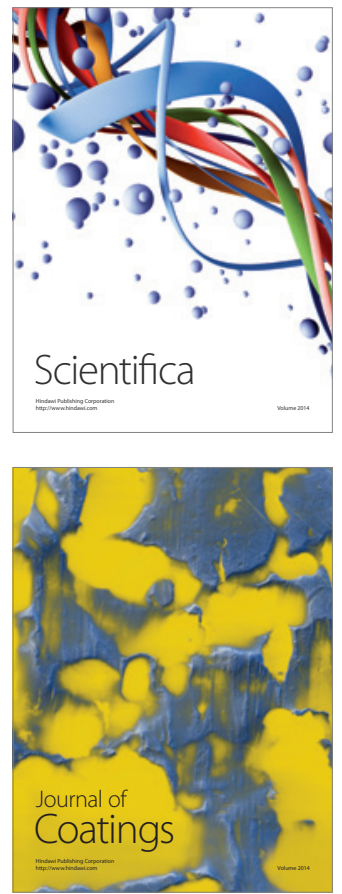
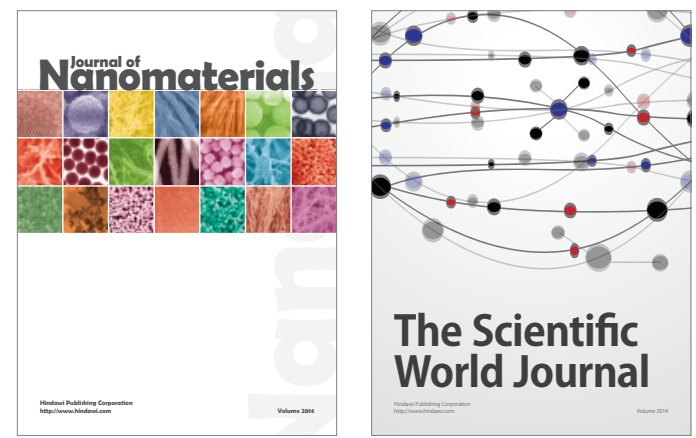

The Scientific World Journal
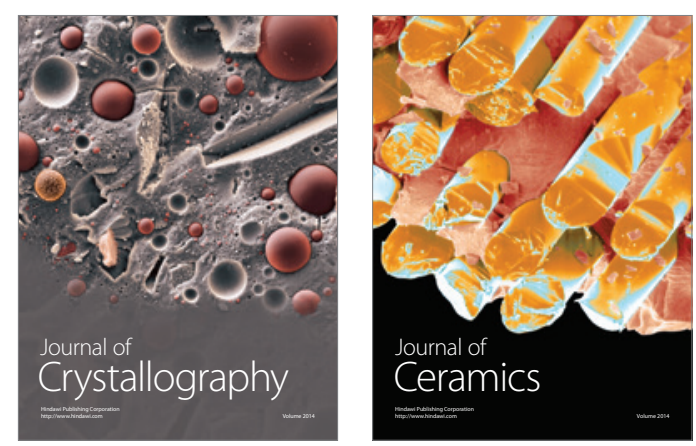
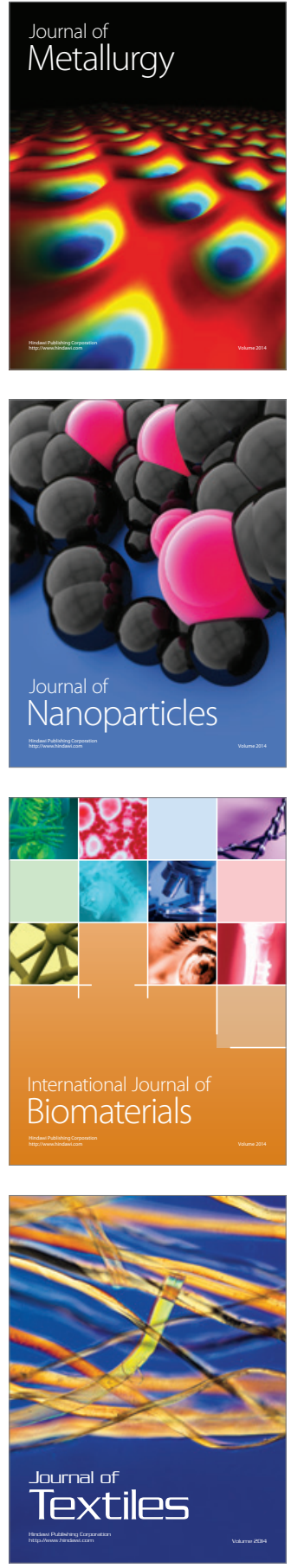